\title{
El fanático de la ópera: Etnografía de una obsesión*
}

The opera fan: ethnography of an obsession

0 Fanático da opera: Etnografia de uma obsessão

Fecha de entrega: 24 de agosto de 2013

Fecha de aprobación: 20 de diciembre de 2013

Claudia Patricia Giraldo A.**

Crisotemis: Nuestro hermano está aquí y el amor

Fluye como el aceite y la mirra

¡Todo es amor!

¿Quién es capaz de vivir sin amor?

RichaRd STRAuss, Electra

El amor es sentimiento, afecto, inclinación y entrega a alguien, mientras que la obsesión es una perturbación anímica producida por una idea fija. Sentimiento y perturbación son cosas distintas y producen comportamientos bien diferentes. Sin embargo, el amor puede experimentarse como una idea con tenaz persistencia y como un deseo incontrolable.

* Benzecry, C. (2012) El fanático de la ópera: Etnografía de una obsesión. Buenos Aires: Siglo XXI editores. 315p. ISBN: 9789876292146

** Docente Facultad de Filosofía y Letras de la Universidad Santo Tomás, Colombia.

1 Fragmento de la ópera Electra, compuesta por Richard Strauss estrenada en enero de 1909. Tomado de www.kareol.es 
Gracias a él podemos sentir una enorme felicidad, un profundo dolor, ansiedad y desequilibrio o bailar y sonreír estúpidamente por la calle, suspirar y anhelar el reencuentro con la persona que amamos o que nos hace perder la perspectiva. Es por esto que estar enamorados nos motiva, nos levanta y nos ayuda a conciliar el sueño y por el contrario el desamor, el desengaño o el desaire hacen que perdamos el sueño y las ganas de vivir. Si creemos en esta afirmación, el amor y la obsesión no son tan diferentes y por el contrario parecen tener vínculos estrechos.

Pese a esta similitud, el amor tiene buena fama: gritar a los cuatro vientos que estamos enamorados o llorar a mares por causa del desamor es aceptado. Por el contrario, la obsesión la descalificamos describiéndola como un patrón de comportamiento inadecuado, ¡un trastorno! En el estudio que reseño a continuación, Etnografía de una obsesión, Claudio Benzecry hace el perfil del amor-obsesión hacia la ópera, describiendo la forma en que esta se convierte en el sentido de vida de mujeres y hombres argentinos, de diferentes edades, clases sociales y profesiones, a quienes bautiza como fanáticos de la ópera. El autor le devuelve a la obsesión algo de su honor, destacando su capacidad productiva y negando su supuesto carácter incapacitante.

La comprensión del amor-obsesión es una empresa, que por obvias razones, casi siempre es dejada en manos de la literatura o la filosofía, ¿quién intentaría explicar desde la ciencia las razones de una exclamación como "mi deseo de quedarme vence a mi voluntad de partir!... ¡Ven, muerte, y sé bienvenida! Julieta lo quiere”. Sin embargo, Benzecry sigue su propia obsesión y se propone entender desde la sociología lo que significa amar algo. Él afirma que “[...] las personas usan la metáfora del amor para pensar la propia formación de la subjetividad, pero también la trascendencia de esa subjetividad". Comprender el amor por la ópera y las rutas que condujeron a diferentes personas a ser consumidores devotos de esta es pues el objetivo central de su investigación.

La importancia de este estudio radica, por una parte, en el interés social y académico que tiene el amor-obsesión sin los prejuicios de la patologización y, por otra, en la apertura que brinda a las investigaciones en ciencias sociales para renovar y enriquecer la forma en que entienden el carácter social del gusto.

Esta investigación da cuenta de la distancia y la irregularidad de la teoría frente al caso particular de Buenos Aires. En consecuencia, el problema de investigación es cómo entender que personas de diferentes ciudades, clases sociales y edades amen la ópera. 
¿Cómo explicar que, a diferencia de otras ciudades y teatros del mundo, en Buenos Aires y, más específicamente, en el Teatro Colón se promoviera la expansión de la ópera en oposición a los intentos de cierre y elitización, y que por lo tanto su público sea de diferentes orígenes y no corresponda únicamente a la clase alta?

Benzecry afirma que "Buenos aires no encaja $[\ldots]$ ni en la propuesta bourdieana ni en las teorías antropológicas sobre lo sagrado y lo profano".

El investigador demuestra que no se trata de un gusto de élite que se hereda a través de los lazos familiares y que suele presentarse como una marca de distinción de clase y dignidad. En contraste, y haciendo uso de la tan mentada frase "fue amor a primera vista", destaca que muchos de los que asisten a la ópera son espectadores que en la adultez y por un acto fortuito de iniciación se convierten en asiduos fanáticos de la ópera.

Este tipo de relación con la ópera se caracteriza porque es un amor que tiene tanto tintes de experiencia sagrada como rasgos de una experiencia popular y profana, una experiencia que en mucho se parece a la pasión por un espectáculo como el futbol, como dice el autor.

El libro está estructurado en tres partes: en la primera, titulada "Telón de fondo", Benzecry deja establecido por qué Buenos Aires y los fanáticos de la ópera no encajan en las teorías sociológicas que ven en el gusto una forma de reproducción y cierre social. La segunda parte, que llama "Primer plano", es propiamente el trabajo de campo; aquí describe detalladamente a los fanáticos que asisten al sector del paraíso o sector de a pie, sus procesos de iniciación y las diferentes formas de sacrificio y compromiso afectivo que tienen con la ópera. Cierra su estudio abriendo las puertas del Colón, dado que encuentra una línea narrativa que une la experiencia en el interior del teatro y la interdependencia que tiene con lo que sucede en el exterior, en Argentina. El amor-obsesión por la ópera, nos dice el escritor, está vinculada con otros ámbitos de la vida social especialmente con el pasado en el que se instituyó un modelo idealizado de nación junto a los principios de la misión civilizadora de la alta cultura argentina.

El autor nos presenta biografías de devotos a la ópera que van a las partes superiores del teatro y del carácter sagrado que le han ido atribuyendo. En una evidente referencia a las teorías de $\mathrm{H}$. Becker, describe la carrera del fanático que va desde su 
iniciación hasta llegar al amor-obsesión hacia la ópera. Benzecry sigue cuidándose de limitar el gusto al origen social del fanático y se dirige hacia la comprensión de los procesos mediante los cuales se forma el gusto, los espacios donde esto ocurre y las etapas de este proceso.

Aunque con la rigidez narrativa que suelen tener las ciencias sociales, desde mi punto de vista el escritor mantiene el equilibrio entre el lenguaje especializado y las palabras de los fanáticos entrevistados logrando así transmitir esta experiencia de amor. Más que la descripción de un fenómeno ajeno nos describe su encuentro con los fanáticos. El estilo narrativo que utiliza Benzecry es un factor que complementa perfectamente esta publicación.

A través de los capítulos, asistimos a la ópera, participamos en las situaciones en las que la gente aprende sobre ópera, el aprendizaje informal en las filas, en los entreactos y en las conferencias ofrecidas por los teatros y organizaciones culturales, y presenciamos la transformación de un aprendiz en fanático. Pero acá no termina todo, el proceso de aprendizaje es permanente, es un trabajo intenso de escucha y de asistencia repetida al teatro y sobre todo de compromiso. Finalmente, gracias a los sacrificios surge la escucha "experta" aquella con la que es posible alcanzar estados trascendentes, sentir emociones que conmuevan a través de las voces y la música.

Liu: Tanto amor secreto, e inconfesado, tan grande, que estos tormentos son dulces para mí, porque los ofrezco a mi señor [...] Porque callando, yo le doy, Le doy tu amor $[\ldots]$ Te hago suya, princesa, iy lo pierdo todo! iy lo pierdo todo! ¡Incluso la esperanza imposible! ¡Atadme! ¡Torturadme! ¡Dadme tormentos y dolores!

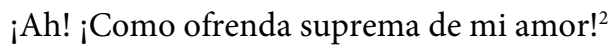

2 Fragmento del acto tercero de la ópera Turandot de G. Puccini. Se estrenó en abril de 1926. Tomado de www.kareol.es 
Comprendemos que el gusto como práctica social implica entender que lo que está en juego no es tanto el honor (teoría tradicional) como la trascendencia. Se trata de un proceso de autotrascendencia que requiere disciplina, sacrificio y un trabajo constante sobre sí. Los fanáticos traspasan límites, pero no se trata de límites de clase, sino de límites de conocimiento a partir del cual logran un más allá de sí mismo, una distinción y reconocimiento como fanáticos dentro del mundo de la ópera y un sentido para sus vidas.

El principal resultado de la propuesta de Benzecry es que estudiar el carácter social del gusto (el apego estético) debe dirigirse hacia las mediaciones entre la estructura social y el gusto. El énfasis se hace en los elementos que contribuyen a transformar la atracción inicial en una pasión y apego permanente y en la forma en que los otros fanáticos intervienen en este proceso. En esos espacios es donde se producen y transforman las representaciones y caracterizaciones de la ópera y donde existe la posibilidad de que se emprenda la "carrera" hacia la trascendencia y el aprendizaje de la experiencia de gozo.

Por otro lado, al presentar la obsesión en términos de destreza y experiencia logra quitarle el peso que la define como patología y, por tanto, como desorden y enfermedad; hacerlo la carga de un matiz erótico. Esta apuesta por un acercamiento superficial, en el sentido no de falta de profundidad, sino de un concentrarse en eso que el autor denomina primer plano, comprende el gusto como un "verdadero amor" que tiene sus límites, sus reglas situadas, sus formas de apreciación y compromiso específicos, y que existe en medio de un complejo juego entre lo colectivo y lo individual.

Por último, el fenómeno de los fanáticos de la ópera problematiza la idea de que los valores sociales siempre son compartidos por todas las personas pertenecientes a una clase pueden ser de hecho contradictorios y relativos. Esta forma de presentar los resultados nos permite ver a la cultura no como una fuerza coercitiva y homogénea que nos antecede; por el contrario, los comportamientos están lejos de ser respuestas mecánicas, se trata de prácticas que se construyen en las interacciones concretas. El gusto, visto de esta manera, es una serie de oportunidades y de pequeños pasos, de cómo estos se van relacionando con restricciones e idealizaciones y con rutinas que pueden ser previsibles pero al mismo tiempo pueden ser creadoras y en consecuencia impredecibles. 
Es grato leer este estudio y ojalá que muchas más personas lo hagan. Es muy placentero encontrarse con un texto que le devuelve al gusto algo del amor-obsesión que lo constituye y que nos enfrenta, desde la sociología y la antropología, a las emociones, a aquello que asalta la mente, a los patrones que aparentemente seguimos mecánicamente y sin sentido.

Tannhäuser: ¡Bendito sea el dios del amor que pulsó las cuerdas de mi arpa y te habló a través de mis canciones! Él me ha guiado hasta ti.

Elizabeth: ¡Bendita sea esta hora!

¡Bendito sea quien me ha traído la buena nueva de tu presencia!

Radiante de felicidad sonríe el sol a mi alrededor, Me despierto a una vida nueva... ¡Inmensa alegría me colma! ${ }^{3}$

3 Fragmento del segundo acto de la ópera Tannhäuser, escrita por Richard Wagner en 1861. Tomado de www.kareol.es 